\title{
Climate and grazing control nurse effects in an Ecuadorian dry shrubby community
}

\begin{abstract}
Positive plant interactions have strong effects on plant diversity at several spatial scales, expanding species distribution under stressful conditions. We evaluated the joint effect of climate and grazing on the nurse effect of Croton wagneri, by monitoring several community attributes at two spatial scales: microhabitat and plant community. Two very close locations that only differed in grazing intensity were surveyed in an Ecuadorian dry scrub ecosystem. At each location, two $30 \times 30-\mathrm{m}$ plots were established at four altitudinal levels (1500, 2630, 1959 and $2100 \mathrm{~m}$ asl) and 40 microsites were surveyed in each plot. Croton wagneri acted as community hubs, increasing species richness and plant cover at both scales. Beneath nurses mean richness and cover values were 3.4 and $21.9 \%$, and in open areas 2.3 and $4.5 \%$, respectively. Magnitude of nurse effect was dependent on climate and grazing conditions. In ungrazed locations, cover increased and diversity reduced with altitude, while grazed locations showed the opposite trend. In ungrazed plots the interactions shifted from positive to negative with altitude, in grazed locations interactions remained positive. We conclude that the nurse effect is a key mechanism regulating community properties not only at microsite but also at the entire community scale.
\end{abstract}

Key Words: altitude, biotic indices, community ecology, Croton wagneri, diversity, Ecuador, environmental gradient, facilitation, patch structure, spatial scale

\section{INTRODUCTION}

Understanding the mechanisms driving the maintenance of species diversity in plant communities has remained central to ecology (Callaway 2007). It is well known that plant-plant interactions and especially positive ones have strong direct and indirect effects on plant diversity at different spatial scales (Callaway 1997, Crain \& Bertness 2006, Soliveres et al. 2011). Nurse plants improve habitat conditions for less-tolerant species and, as a consequence, it may locally increase species diversity (Hacker \& Gaines 1997) and expand species distribution over environmental gradients (Crain \& Bertness 2006).

In drylands, vegetation usually occurs as conspicuous patches embedded in a matrix of bare ground (Aguiar \& Sala 1999). These vegetation patches play an important role in community diversity and ecosystem function through seed trapping (Escudero et al. 2004), alleviating harsh conditions (Maestre \& Cortina 2005) and as a refuge

\footnotetext{
${ }^{1}$ Corresponding author. Email: ciespinosa@utpl.edu.ec
}

for herbivores (Aguiar \& Sala 1999). Several studies have evaluated the differences in diversity between cushions and open areas by using well-known interaction indices based on pairwise comparisons between microsites (Armas et al. 2008). However, few studies have scaled up the importance of facilitation to the entire community (Cavieres \& Badano 2009, Tewksbury \& Lloyd 2001, Xu et al. 2010).

Although climate and grazing are acknowledged to be two of the most crucial limiting forces determining plant community assemblage there is little information about the joint effect of the two factors on the effects of nurse plants (Maalouf etal.2012) and eventually on community properties. Our main goal was to evaluate the joint effect of climate stress and grazing pressure on the magnitude of the nurse effect on several community attributes (richness, diversity and plant cover) at two spatial scales (microsite and the entire community). We used altitude as a surrogate of predictable climate variation (Körner \& Paulsen 2004)

A huge effort has been devoted to describing facilitation processes in very different ecosystems. Nevertheless, 
there are no studies exploring this topic in tropical dry ecosystems. We conducted a field survey in the Ecuadorian dry montane scrub ecosystem, which is especially suitable because the community is dominated by a single nurse plant along a very long altitudinal gradient. In this dry ecosystem, the relationship between environmental stress and altitude is opposite of that in other latitudes: climate at low altitudes is more stressful, with low water availability and high temperatures, while climate becomes milder towards higher altitudes with an increase in precipitation (Espinosa et al. 2013).

The working hypotheses are: (1) nurse plants increase species performance and diversity both at the microsite and at the entire community scales under stressful conditions; (2) the nurse effect on community properties is jointly modulated by abiotic stress (altitude) together with biotic disturbance levels (grazed vs. ungrazed); (3) the proportion of species that expanded their distribution range due to the presence of nurse plants, will increase with climatic stress and grazing pressure, since nurse plants would improve local environmental conditions and create herbivore-free gaps; (4) nurse plants exert speciesspecific facilitation effects.

\section{METHODS}

\section{Study area}

Our study was conducted in the Ecuadorian dry montane scrub ecosystem. This ecosystem occurs in some interAndean dry valleys between 1400 and $2500 \mathrm{~m}$ asl and it is characterized by a strong and long dry season (Figure 1). Vegetation cover appears as patches dominated by Croton wagneri Müll. Arg. embedded in a matrix of bare ground. Croton wagneri is an endemic but locally abundant shrub (Ulloa \& Jørgensen 1995). It grows together with other rare xerophytic and spiny perennial species (Sierra 1999).

The valley of Catamayo (Loja province, Ecuador), one of the best-preserved dry montane scrub ecosystems, constitutes an ideal natural model because the shrubby community dominated by $\mathrm{C}$. wagneri extends throughout a long altitudinal gradient. We selected one of these stands, in the locality named Chinchas, which has experienced seasonal grazing by cattle over the last $20 \mathrm{y}$. Grazing occurs during the short rainy season (between January and April) with stock densities of 13 animals ha ${ }^{-1}$. We selected also another locality $4 \mathrm{~km}$ away (Alamala) that has remained undisturbed during the same period. Both localities were similar in relation to the geological substrata, inclination, orientation and rainfall distribution.

As there are no reliable climatic data available in the area, temperature and precipitation sensors (Extech RHT10) were placed directly on the soil at three altitudinal levels (1500, 1690 and $2100 \mathrm{~m}$ asl) in Alamala. Measures were recorded each minute between January 2010 and December 2011. We built a climatic diagram (Walter \& Lieth 1960) using the package climatol implemented in R environment (Guijarro 2011). Around $80 \%$ of precipitation was recorded between February and March (Figure 1). Mean temperature at soil level and mean precipitation differences between upslope and downslope locations were $4.5^{\circ} \mathrm{C}$ and $139 \mathrm{~mm}$ respectively (Figure 1 ). Water deficit $(\mathrm{P}<2 \mathrm{~T})$ was prevalent 10 months a year. This pattern was consistent at the three altitudinal levels.

\section{Sampling design}

In both localities, the altitudinal range was evenly divided to establish sampling sites at four altitudes, grazed locations were located between $1450 \mathrm{~m}$ to $2100 \mathrm{~m}$ and ungrazed locations between $1550 \mathrm{~m}$ and $1950 \mathrm{~m}$. At each altitude, two $30 \times 30-\mathrm{m}$ plots were established (16 plots) on a representative and homogeneous portion of the scrubland. Plots at each altitude were located no more than $500 \mathrm{~m}$ apart from each other (mean distance was $200 \mathrm{~m}$ ). In each plot four 30-m-long transects parallel to the maximum slope and $8 \mathrm{~m}$ apart from each other were established. In each transect, 20 contiguous $1.5 \times 1.5-\mathrm{m}$ quadrats were placed and the cover of every perennial plant species was recorded. Total cover at plot level (canopy cover, hereafter) was estimated as the average perennial plant cover of the 80 quadrats surveyed per plot. Lengths and widths of patches and interpatches (open areas) intercepted by the transect were measured, and in this study we used the Minimum Interpatch Length (MINIL) index to characterize the patchy structure of the vegetation (Tongway \& Hindley 2004).

In each plot, 20 mature C. wagneri individuals were randomly selected and tagged (320 C. wagneri patches). We measured the maximum perpendicular axes of each patch containing the nurse plant, in order to estimate its patch size by fitting it to an ellipse (Cavieres \& Badano 2009). We recorded abundance and cover of every perennial plant species (perennial cover, hereafter), excluding cover of the nurse plant, in the whole area below the canopy of each $C$. wagneri plant using as many $0.5 \times 0.5-\mathrm{m}$ grid quadrats as necessary. Subsequently, the same numbers of grid quadrats were surveyed in the adjacent open areas (at least $1 \mathrm{~m}$ away from any plant of C. wagneri).

\section{Effects of nurse plants on diversity}

Diversity effects of nurse plants were calculated at two spatial scales: microsite and plot by using some biotic indices. Microsite scale comprises each $C$. wagneri patch 

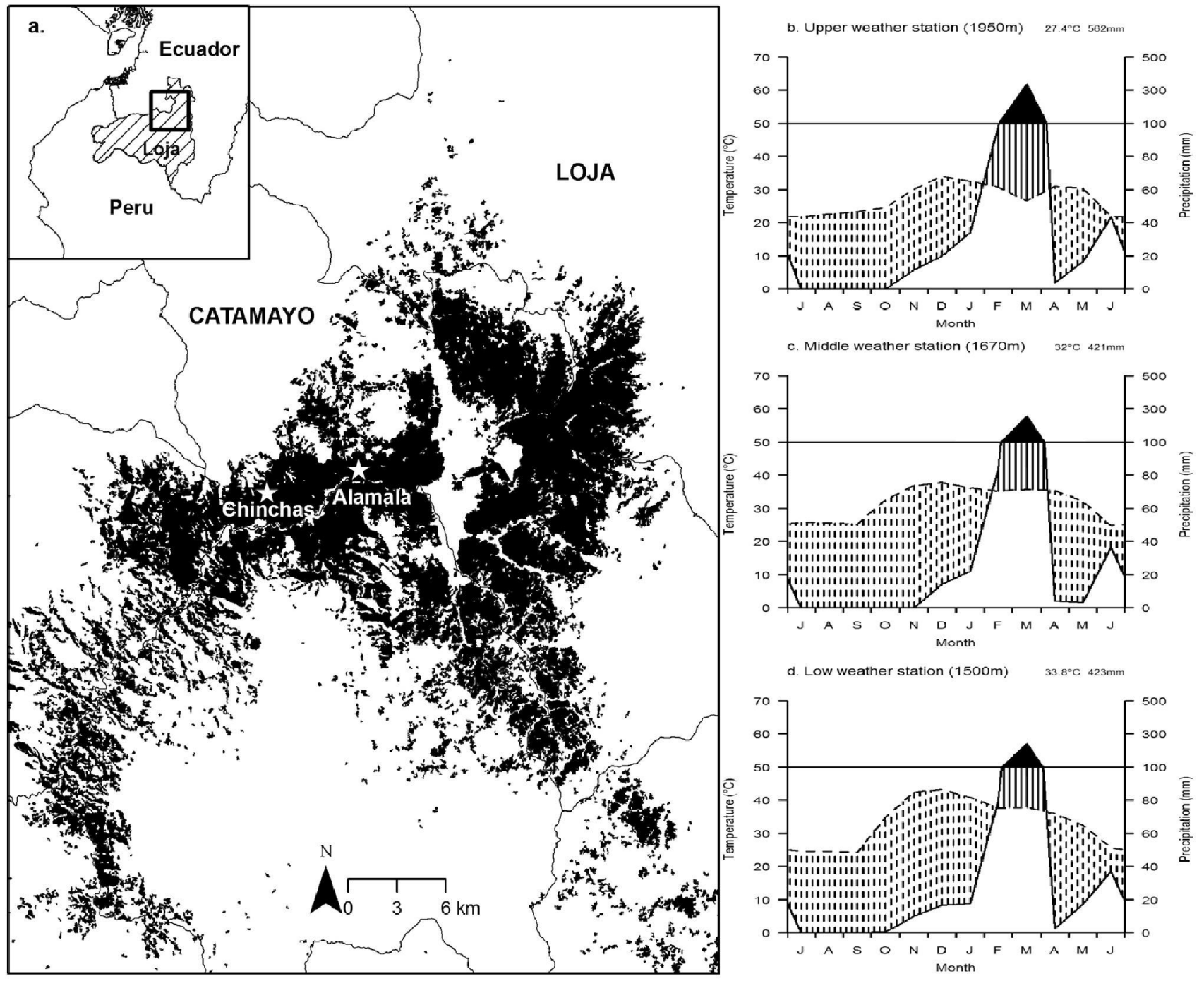

Figure 1. Study area in southern Ecuador and climatic diagrams of three weather stations at different altitudes. The small figure represents the Loja province (striped). The large figure shows distribution area of the Ecuadorian dry montane scrub ecosystem (black) in the Catamayo and Loja districts, and the two surveyed locations: Chinchas and Alamala (white stars) (a). Climatic diagram in the upper weather station (b), middle weather station (c) and lower station (d) in Alamala. Black areas and solid lines represent humid months, dotted areas arid months. Altitude, mean annual temperature and total annual precipitation of each weather station are shown. Mean temperature and total precipitation per month are represented from July 2010 to June 2011.

with its corresponding open area, and the plot level refers to richness and average perennial cover values at the whole plot $(30 \times 30-\mathrm{m}$ plots). Diversity was estimated by means of the inverse Simpson index (Jost 2006).

In order to detect plant-plant interactions and to quantify their effect on diversity at both community scales, we used four biotic indices, since plant interactions are not easily and univocally measured (Maestre et al. 2005). These indices were computed using both plant richness and perennial cover as surrogates of community and plant performance, respectively. We used the Relative Interaction Index (RII) proposed by Armas et al. (2004) to establish the net balance of the interaction between C. wagneri patches and the rest of the species in each combination of altitude and grazing intensity. This index is based on the idea that the higher the richness or cover values in a certain microhabitat, the more benign microhabitat conditions are for the plant community (Armas et al. 2004, Choler et al. 2001). We calculated the RII in terms of richness and perennial cover at the microsite scale, as follows,

$$
\mathrm{RII}_{\mathrm{r}}=\frac{\mathrm{R}_{\text {nurse }}-\mathrm{R}_{\text {open }}}{\mathrm{R}_{\text {nurse }}+\mathrm{R}_{\text {open }}}
$$

where, $\mathrm{R}_{\text {nurse }}$ : richness below C. wagneri, $\mathrm{R}_{\text {open }}$ : richness in open areas. 
In terms of perennial cover per $\mathrm{C}$. wagneri patch:

$$
\text { RII }_{\mathrm{c}}=\frac{\mathrm{C}_{\text {nurse }}-\mathrm{C}_{\text {open }}}{\mathrm{C}_{\text {nurse }}+\mathrm{C}_{\text {open }}}
$$

where, $\mathrm{C}_{\text {nurse }}$ : total perennial cover below the canopy of C. wagneri patches, $C_{\text {open }}$ : total perennial cover in open areas.

In order to estimate the proportion of the species that increased their distribution range due to the presence of nurse plants, we built the following Obligate Species Index (OSI) and Expanded Distribution Index (EDI) at the microsite scale based on the Relative Interaction Index (RII; Armas et al. 2004). Both EDI and OSI indices provide information about the relative dominance of the species strictly related to each microsite: beneath patches or in bare areas

$$
\begin{array}{r}
\text { OSI }=\frac{\left(S_{\text {nurse }}-S_{\text {open }}\right)}{\left(S_{\text {nurse }}+S_{\text {open }}\right)} \\
\text { EDI }=\frac{\left(S_{\text {nurse }}-S_{\text {open }}\right)}{\text { Total richness }}
\end{array}
$$

where, $S_{\text {nurse }}$ is the species number occurring exclusively under the canopy of nurse plants and $S_{\text {open }}$ is the species number occurring only in the open area in each nurse/open sample pair; total richness includes the species present both beneath and outside the nurse plant. OSI and EDI indices differ in the amount of species considered for calculation of each index, OSI only includes the species exclusively linked to one of the two microsites avoiding those species that appeared in both of them (at microsite scale), while EDI considers every species present in each nurse-open system. These two indices are bounded between 1 and -1 and have the same mathematical properties of the well-known RII (Armas et al. 2004).

In order to assess the Facilitation Effect Size $\left(\mathrm{FES}_{\mathrm{sp}}\right)$ of C. wagneri patches on the performance of the eight most abundant perennial species in the community, we created an index that measures the differences in cover for each species between the two microhabitats (nurse and open areas) at the plot scale.

$$
\mathrm{FES}_{\mathrm{sp}}=\frac{\sum_{1}^{20}\left(\frac{\mathrm{C}_{\text {nurse }}-\frac{\mathrm{C}_{\text {open }}}{\mathrm{spi}}}{\mathrm{spi}}\right)}{\sum_{1}^{20} A_{\text {nurse }}}
$$

where, $C_{\text {nurse/spi }}$ is the cover of species $i$ beneath $C$. wagneri patches, $C_{\text {open/spi }}$ is the cover of species $i$ in open areas, and $A_{\text {nurse }}$ is the patch area. Values for the 20 patches in each plot were summed up to obtain the Facilitation Effect Size index for each species per plot. The eight species evaluated were: Baccharis salicifolia Ruiz \& Pavon (Asteraceae), Croton wagneri Müll. Arg. (Euphorbiaceae), Gaya calyptrata (Cav.) Kunth ex K. Schum. (Malvaceae), Lantana canescens Kunth (Verbenaceae), Mimosa sp. (Fabaceae), Onoseris sp. (Asteraceae), Opuntia quitensis Engelm. (Cactaceae) and Stachytarpheta steyermarkii Moldenke (Verbenaceae).

\section{Data analyses and model fitting}

Non-linear mixed models (NLMM) were used to model community properties such as richness, diversity (inverse Simpson) and perennial cover (excluding canopy cover of $C$. wagneri patches), as well as the biotic indices built to estimate facilitation (five indices). The Relative Interaction Indices $\left(\mathrm{RII}_{\mathrm{r}}, \mathrm{RII}_{\mathrm{c}}\right)$, the Obligate Species Index (OSI) and the Expanded Distribution Index (EDI) were modelled both at microsite and plot scales whereas the facilitation effect size (FES) for the most abundant species was modelled only at the plot scale. We used as fixed predictors the microsite (beneath patch vs open area), altitude (continuous variable), grazing (grazed vs. ungrazed) and the interaction altitude $\times$ grazing. We also included in the model the following covariables: the Minimum Interpatch Length (MINIL) as a surrogate of the patchy structure of the vegetation, total canopy cover per plot as a surrogate of primary productivity (Maestre \& Escudero 2009), and patch size. Plot was included as a random factor in order to account for spatial autocorrelation and other potential biases due to some unobserved trends related to our field experimental design (Warren 2010). To account for non-monotonic responses along the altitude gradient, we built models with and without the quadratic term of altitude and, in the first case, with and without its interaction with grazing. The convenience of including these terms was evaluated using the AIC criterion.

Since our variables were asymptotically bounded between a minimum and a maximum value, we fitted models based in two-parameter logistic functions $\frac{e(a+b x)}{\left(1+e^{(a+b x)}\right)}$, expanded and translated to fit the responses between the corresponding bounding limits (Legendre \& Legendre 1998). This approach releases the analysis from the need to transform the data in order to fit any of the probability distributions usually assumed by GLMs (O'Hara \& Kotze 2010). We performed the usual model diagnostics and when apparent violations were found, we refitted the standard errors of the coefficients by adjusting the estimated variance-covariance matrix by means of sandwich estimators (White 1996). Statistical analyses were performed with the packages stats, nlme (Pinheiro \& Bates 2000) and nls (Bates \& Chambers 1992) in the R environment.

\section{RESULTS}

Overall, 26 perennial species were recorded in this study. Mean $( \pm \mathrm{SE})$ species richness per $C$. wagneri patch and open area was $3.4 \pm 1.3$ and $2.3 \pm 1.1$, respectively. Mean perennial cover (excluding C. wagneri) was $21.9 \% \pm$ $18.8 \%$ and $4.5 \% \pm 8.2 \%$ beneath patches and in open 
Table 1. Coefficients of non-linear mixed models (NLMM) for community attributes at microsite level; perennial cover (excluding cover of the nurse plant), richness, diversity (inverse Simpson) and four biotic indices measured at the microhabitat scale: RIIr: Relative Interaction Index in terms of richness, RIIc: Relative Interaction Index in terms of cover, OSI: Obligate Species Index, EDI: Expanded Distribution Index. MINIL: Minimum Interpatch Length, Nurse/Open: Nurse (0), Open (1). Total canopy cover per plot is used as a surrogate of primary productivity. Patch size: total area surveyed for each nurse/open sample pair. A quadratic term is showed as ${ }^{2}$. n.s.: Not significant. ${ }^{*}: \mathrm{P}<0.05 ;^{* *}: \mathrm{P}<0.01$; $^{* *}$ : $\mathrm{P}<0.001$. n.i.: Variables not included in the model.

\begin{tabular}{lccccccc}
\hline Predictor & Perennial cover & Richness & Diversity & RIIr & RIIc & OSI & EDI \\
\hline Intercept & $74.1^{* * *}$ & n.s. & n.s. & $4.1^{* *}$ & $-47.9^{* *}$ & $5.8^{*}$ & $4.1^{* * *}$ \\
Altitude & $-0.1^{* * *}$ & n.s. & n.s. & $-0.002^{* *}$ & $0.06^{* *}$ & $-0.002^{*}$ & $-0.002^{*}$ \\
Altitude $^{2}$ & $<0.001^{* * *}$ & n.s. & n.s. & n.i. & $<-0.001^{* *}$ & n.i. & n.i. \\
Grazing & $-80.7^{* * *}$ & n.s. & $-35.4^{* *}$ & $-5.6^{* * *}$ & $68.6^{* *}$ & $-5.7^{* *}$ & $-5.4^{* * *}$ \\
Altitude $\times$ Grazing & $0.1^{* * *}$ & n.s. & $0.04^{* *}$ & $0.003^{* * *}$ & $-0.1^{* * *}$ & $0.003^{* *}$ & $0.003^{* * *}$ \\
Altitude $^{2} \times$ Grazing & $<-0.001^{* * *}$ & n.s. & $<-0.001^{* *}$ & n.i. & $<0.001^{* * *}$ & n.i. & n.i. \\
Nurse/Open & $-1.8^{* * *}$ & $-0.6^{* * *}$ & $-0.6^{* * *}$ & n.i. & n.i. & n.i. & n.i. \\
MINL & $-1.4^{* * *}$ & n.s. & n.s. & n.s. & $-2.4^{* *}$ & n.i. & n.i. \\
Canopy cover & $0.02^{* * *}$ & n.s. & n.s. & n.s. & n.s. & $-0.002^{* *}$ & n.s. \\
Patch size & $-0.02^{* * *}$ & $0.04^{* * *}$ & $0.02^{* * *}$ & $-0.04^{* * *}$ & n.s. & $-0.04^{* *}$ & $-0.04^{* * *}$ \\
\hline
\end{tabular}

Table 2. Coefficients of non-linear mixed models (NLMM) for richness and perennial species cover (excluding nurse cover) at plot scale. Nurse/Open: Nurse (0), Open (1). Canopy cover per plot is used as a surrogate of primary productivity. n.s.: Not significant. ${ }^{* * *}: \mathrm{P}<0.001$.

\begin{tabular}{lcc}
\hline Predictor & Perennial cover & Richness \\
\hline Intercept & $23.7^{* * *}$ & n.s. \\
Altitude & $-0.01^{* * *}$ & n.s. \\
Grazing & $-25.1^{* * *}$ & n.s. \\
Altitude $\times$ Grazing & $0.01^{* * *}$ & n.s. \\
Nurse/Open & $-2.4^{* * *}$ & $-1.2^{* * *}$ \\
Canopy cover & n.s. & n.s. \\
\hline
\end{tabular}

areas, respectively. The most abundant perennial species were Lantana canescens (36.5\%), Gaya calyptrata (18.9\%) and Stachytarpheta steyermarkii $(16.2 \%)$.

Fewer species and more reduced perennial cover occurred in open areas than in patches. Furthermore, four species (Lycianthes lycioides (L.) Hassl.(Solanaceae), Euphorbiatirucalli L. (Euphorbiaceae), Puyalanata (Kunth) Schult. f. (Bromeliaceae), and Peperomia peltigera C. DC. (Piperaceae) $-16 \%$ of the total perennials), occurred exclusively under $C$. wagneri patches, whereas no species grew exclusively in open areas. At high altitudes (more benign conditions) perennial cover under $C$. wagneri was reduced both at microsite and plot scales (Tables 1,2). At the microsite scale, cover was better explained by the inclusion of a quadratic term for altitude in the definitive model. This means that environmental conditions at both ends of the altitudinal gradient exerted a relatively similar effect on perennial cover different from middle altitudes (Figure 2). However, altitude had no effect on species richness or diversity. Grazed locations showed less perennial cover and lower diversity but similar species richness.

A significant interaction between altitude and grazing on perennial cover happened both at the microsite and plot scales, and on diversity exclusively at microsite scale (Figure 2). In the ungrazed locality, perennial cover showed higher values at lower and upper altitudes and low cover values at middle altitudes, both beneath nurse plants and in open areas. In contrast, under grazing conditions, cover values for both microsites remained almost constant along the altitudinal gradient. A similar trend was observed at the entire community level. Microsite diversity showed opposing trends in grazed and ungrazed localities (Figure 2c); while in the ungrazed locality diversity increased towards the milder high altitudes, under grazing conditions maximum diversity occurred at middle altitudes (Figure 2c).

The Relative Interaction Indices (RIIc and RIIr for cover and richness respectively) showed a positive net effect of facilitation except in the ungrazed locality at the milder highest altitudes, where the nurse effect vanished or even became detrimental (Figure 3a,b). Facilitation intensity was largely determined by the interaction between grazing and altitude (Table 1). In the ungrazed locality, the nurse effect increased species richness at the most stressful low altitudes while no nurse effect was detected at the mild high altitudes. In contrast, under grazing conditions, the nurse effect on species richness was more important at the highest altitudes, while when climate stress and grazing co-occurred at low altitudes the positive effect of nurse plants almost vanished. This trend was also observed with the Obligate Species Index (OSI) and the Expanded Distribution Index (EDI) at the microsite scale (Table 1, Figure 3). These indices revealed that in ungrazed conditions, the proportion of obligate species associated with the microhabitat created by the nurse plant increased towards the most stressful low altitudes. In other words, nurse plants improved environmental conditions for a larger proportion of species at low altitudes. The opposite effect was observed under grazing conditions, where the proportion of species tightly associated with the nurse microhabitat increased towards higher altitudes. However, no significant effects 

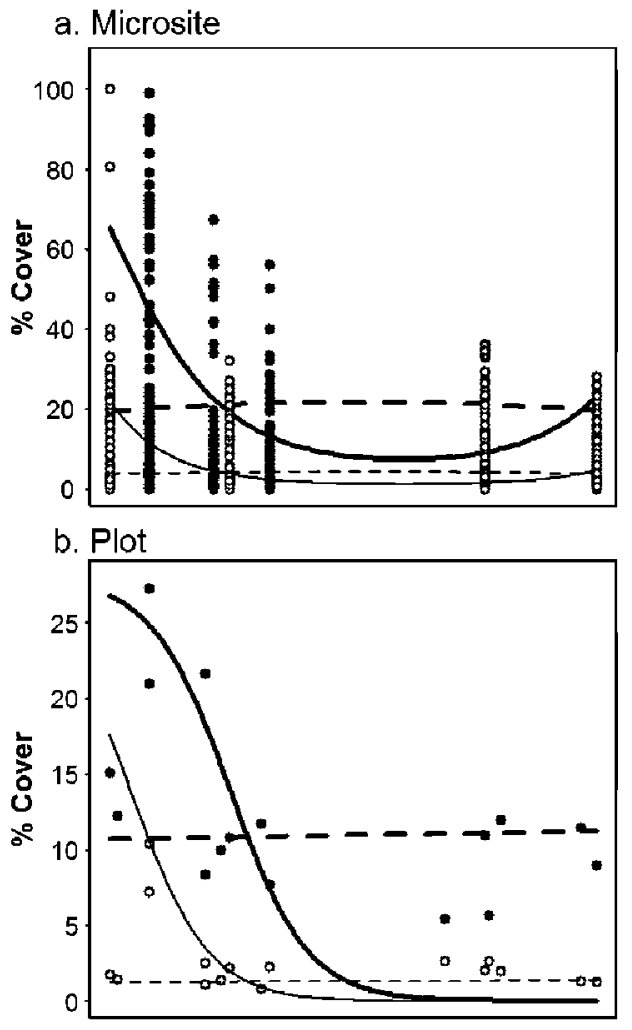

c. Microsite

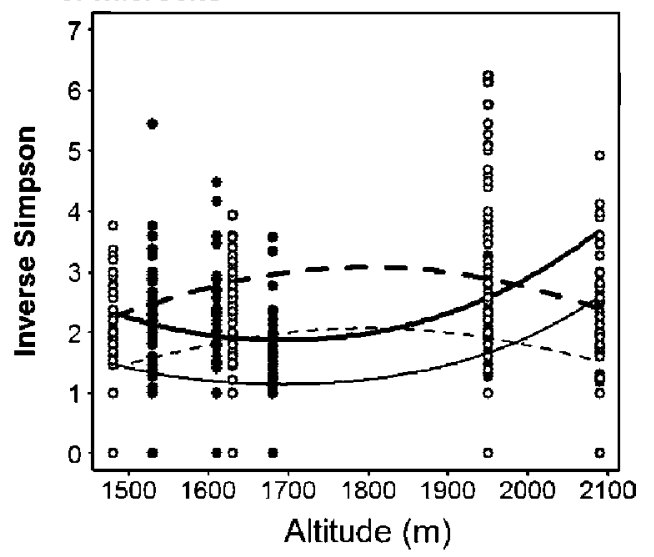

Figure 2. Non-linear mixed models for plant cover at microsite (a) and plot (b) scales and for diversity at plot scale (c). Circles represent samples: black circles correspond to undisturbed locations and white circles to grazed locations of the Ecuadorian dry montane ecosystem. Solid lines represent the fitted model for undisturbed locations (thick line: beneath nurse, thin line: open zone) and dotted lines for grazed locations (thick line: beneath nurse, thin line: open zone).

of altitude or grazing on these indices were observed at the plot level ( $\mathrm{P}>0.05$; data not shown).

Performance of the most abundant perennial species at the plot level in terms of cover under $\mathrm{C}$. wagneri, measured by the Facilitation Effect Size $\left(\mathrm{FES}_{\mathrm{sp}}\right)$ index, showed a significant effect of the nurse plant on only two species: Croton wagneri (saplings living beneath canopy) and Opuntia quitensis (Figure 3e,f). In ungrazed conditions, the facilitation effect of nurses strikingly increased towards the most stressful end of the altitudinal gradient (low altitudes), while, under grazing conditions, the effect of nurse plants for both species was close to zero along the altitudinal gradient (Table 3).

\section{DISCUSSION}

Our hypothesis about nurse plant effects on community properties is confirmed, i.e. nurse plants increased species diversity not only at the microsite scale but also at the entire community level. We detected four perennial species that were strictly associated with $C$. wagneri patches and never occurred in open areas. The mechanisms involved in this relationship are not easy to establish. Lycianthes lycioides is a bird-dispersed species. Thus, most likely, $C$. wagneri may act as a perch structure for this species which is able to establish beneath its canopy. The other three species (Euphorbia tirucalli, Peperomia peltigera and Puya lanata) are not bird-dispersed and the mechanisms underlying this relationship could be related to micro-environmental amelioration, or to a seed trapping effect beneath C. wagneri canopies.

This reinforces the idea that nurse plants are crucial for determining diversity at the whole community level, especially in stressful environments (Cavieres \& Badano 2009, Michalet et al. 2006). Pioneering studies on the effect of abiotic stress gradients on species diversity suggested that mild environments allow high primary productivity conditions that enhances competition leading to a reduction in species richness (Grime 1973), whereas, under stressful environmental conditions physiological restrictions led to reduced species richness. Our results on the effect of altitude on community properties of the dry tropical shrubland greatly disagree with the above framework, specially at the most stressful low altitudes, and gives conclusive support to the Stress Gradient Hypothesis (SGH) (Callaway 1997). We observed that perennial species cover (excluding adult $C$. wagneri), was higher at low altitudes, both at microsite and plot scales. We suggest that the mechanisms underlying this pattern are related to the nurse effect of $C$. wagneri plants which lessens the abiotic stress and thus enhances plant performance and plant cover within canopied areas.

In this tropical dry ecosystem, diversity showed a Ushaped relationship with altitude in ungrazed conditions. Higher diversity values were detected at both extremes of the climate gradient. Although this U-shaped relationship could seem counterintuitive, Mittelbach et al. (2001) in their review of studies dealing with productivity vs. richness variability, found a substantial number of such patterns. Scheiner \& Jones (2002) suggested that the Ushaped relationships may be due to community transition 

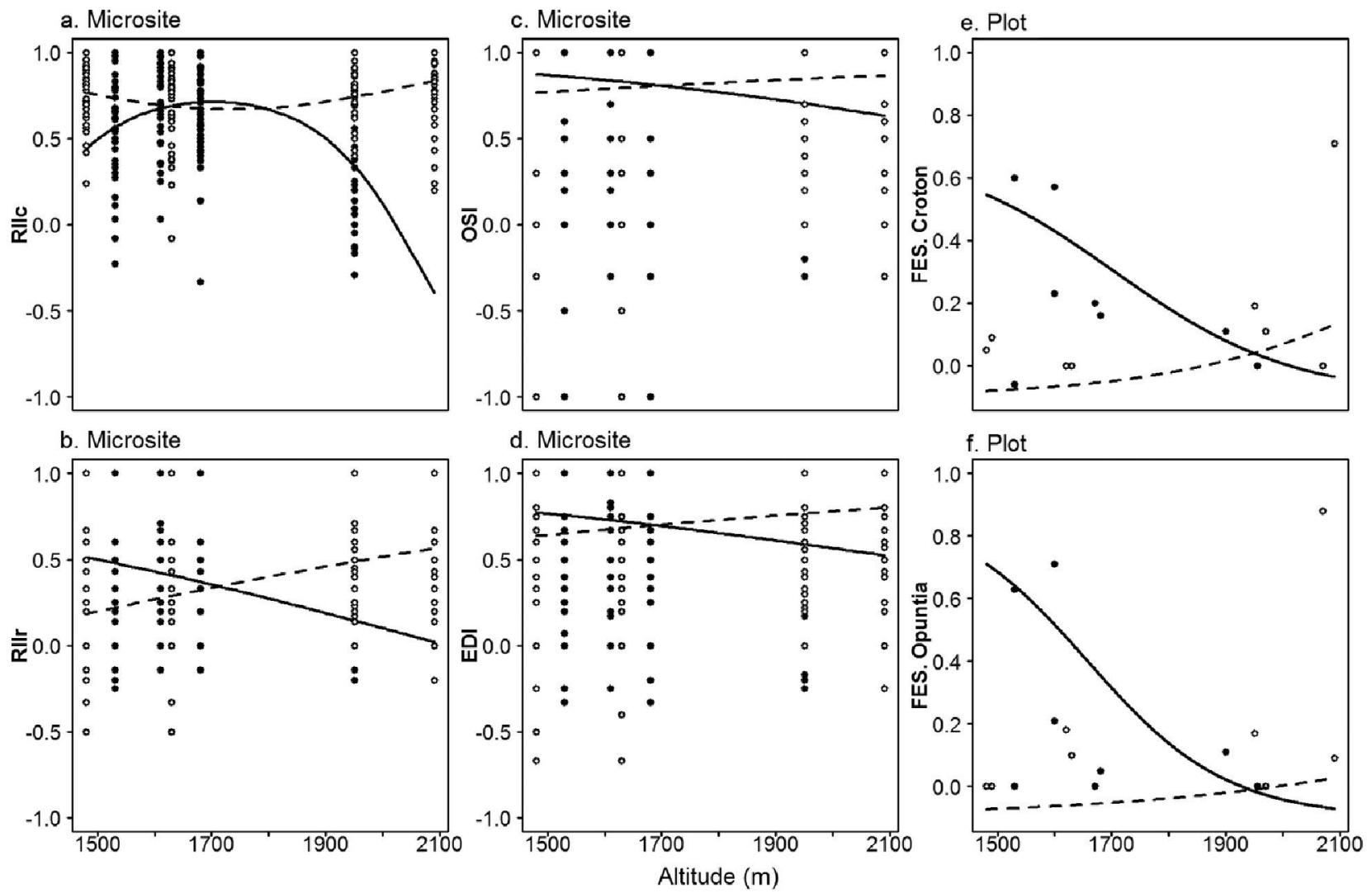

Figure 3. Non-linear mixed models for the biotic indices. The models were evaluated at microsite scale: R IIc: Relative Interaction Index for cover (a), RIIr: Relative Interaction Index for richness (b), OSI: Obligate Species Index (c), EDI: Expanded Distribution Index (d), and at plot scale: FES: Facilitation Effect Size index for Croton wagneri (e) and Opuntia quitensis (f). Circles represent samples: black circles correspond to undisturbed locations and white circles to grazed locations of the Ecuadorian dry montane ecosystem. Solid lines represent the fitted model for undisturbed location and dotted lines for grazed locations.

Table 3. Coefficients of non-linear mixed models (NLMM) for the Facilitation Effect Size (FES) index for the eight most abundant species in the community. Croton: Croton wagneri, Gaya: Gaya calyptrata, mimosa: Mimosa sp., Opuntia: Opuntia quitensis, Stachy: Stachystarpheta steyermarkii, Lantana: Lantana canescens, Baccharis: Baccharis salicifolia, Onoseris: Onoseris sp. Canopy cover: is a surrogate of primary productivity per plot. *: $\mathrm{P}<0.01$.

\begin{tabular}{lcccccccc}
\hline & \multicolumn{7}{c}{ Facilitation Effect Size (FES) index } \\
\cline { 2 - 8 } Predictor & Croton & Gaya & Mimosa & Opuntia & Stachy & Lantana & Baccharis & Onoseris \\
\hline Intercept & n.s. & n.s. & n.s. & $20.05^{*}$ & n.s. & n.s. & n.s. & n.s. \\
Altitude & n.s. & n.s. & n.s. & n.s. & n.s. & n.s. & n.s. & n.s. \\
Grazing & $-21.4^{*}$ & n.s. & n.s. & $-21.2^{*}$ & n.s. & n.s. & n.s. & n.s. \\
Altitude $\times$ Grazing & $0.01^{*}$ & n.s. & n.s. & $0.01^{*}$ & n.s. & n.s. & n.s. & n.s. \\
Canopy cover & n.s. & n.s. & n.s. & $-0.1^{*}$ & $0.04^{*}$ & n.s. & n.s. & n.s. \\
\hline
\end{tabular}

zones close to the limits of the gradient. This is likely to happen in our study, since close to the upper boundary of the C. wagneri scrub community, and related to the increase in water availability, species belonging to the tropical montane forest appear; whereas in the lowest stressful zones, the intensity of nurse effects may increase diversity.

However, when the effect of grazing was superimposed on the abiotic stress gradient, the above-mentioned cover and diversity patterns suffered a substantial change. Plant cover remained quite constant all along the altitudinal gradient in grazed locations, both at the microsite and entire community scales. A possible mechanism underlying this pattern could be related to the foraging behaviour of large herbivores. It has been stated that foragers move slowly across very productive communities and rapidly across less productive ones (Ruyle \& Dwyer 1985), probably because foraging thresholds of large herbivores are reached more quickly in poor patches than in rich ones, causing lower residence time of 
herbivores per patch in unproductive systems (Senft $e t$ al. 1987). Since our study system is a low-productivity semi-arid shrub community, it is likely that cattle and natural herbivores move relatively fast along the entire altitudinal gradient, and consequently they likely act as a homogenizing agent on plant productivity in our system. Obviously, this point deserves specific study.

Surprisingly, diversity in grazed locations showed a humped pattern along the altitudinal gradient with higher values of diversity at intermediate altitudes and lower values at both extremes of the altitudinal range. This pattern along productivity gradients has also been described by Grime (1973). He proposed that under mild conditions competitive interactions usually prevail but when a disturbance agent like grazing joins in, competition intensity reduces and more species can co-occur, increasing total diversity. However, this explanation does not fit with the decay in diversity at the highest altitudes. It is possible that under more benign conditions the abundance of more palatable plant species increase and consequently herbivores may spend more time foraging (Senft et al. 1987) locally removing some plant species. Our study demonstrates that the concurrent effect of climate and grazing exerted a crucial effect on plant community properties. The superimposed grazing pressure dramatically altered the importance of climate on community properties (Graff et al. 2007).

\section{Nurse effect under climate and grazing variation}

Previous studies in alpine (Cavieres et al. 2006), desert (Bowers 2005) and Mediterranean (Escudero et al. 2004) habitats have provided solid evidence for positive plant-plantinteractions, especially with cushion-forming species. The enhancement of the intensity of positive associations along an altitude gradient is one of the most consistent findings (Cavieres et al. 2006). However, predominance of positive versus negative interactions along altitude gradients differs among ecosystems. Thus, in Chilean Mediterranean climate type ecosystems and in tropical dry forests the magnitude of facilitation increases towards lower altitudes, most likely due to limited water availability caused by high temperatures and low precipitation, typical of these zones (Cavieres et al. 2006, Espinosa et al. 2011). Our results are in line with these findings, and, even more, since our study comprised a long altitudinal range $(600 \mathrm{~m})$, we could ascertain that the magnitude of plant-plant interactions, measured as the Relative Interaction Index in terms of cover (RIIc), followed a humped pattern along the altitude gradient. We observed a peak on the magnitude of the nurse effect atintermediate altitudes in ungrazed conditions, probably because at the most stressful lower altitudes plants are not able to sufficiently improve climate harshness and at the middle and upper altitudes competition interactions may prevail, reducing plant cover beneath plants of $C$. wagneri. In the grazed locality nurses had a positive and quite constant effect on plant cover all along the altitudinal gradient. This may reflect the effect of nurse plants as safe sites for species establishment in grazed locations independently of climate conditions.

In order to understand this shift in the intensity and direction of plant interactions, the Obligate Species (OSI) and the Extended Distribution Indices (EDI), allow us to discern some of the mechanisms that may be involved. Both indices point to an increase in the proportion of species tightly associated with nurse plants towards higher altitudes under grazing conditions. These results imply that under grazing pressure the importance of the nurse effect was extended to zones with relatively benign climates, changing the magnitude of nurse effects from competition to facilitation (Oesterheld \& Oyarzábal 2004). This suggests that the primary effect of nurse amelioration along stressful climate gradients is secondly modulated by grazers. As a consequence, under grazing conditions the expected response of facilitation along stress gradients can hardly be found. Our results may help to explain most discrepancies dealing with the generalization of the Stress Gradient hypothesis to other ecosystems (Maestre et al. 2009).

\section{Species-specific response to co-occurring biotic and abiotic environmental limitations}

Climate and grazing influence on species-specific nurse effect was evaluated in terms of cover with the eight most abundant species by means of the Facilitation Effect Size $\left(\mathrm{FES}_{\mathrm{sp}}\right.$ ) index for each species. We found a significant effect of altitude or grazing for two species only: Croton wagneri juveniles and Opuntia quitensis. In both species the magnitude of the nurse effect was larger in ungrazed locations at low altitudes, where the abiotic environmental stress could be overcome by nurse plants, resulting in an increase of plant cover beneath plants of C. wagneri. At the milder high altitudes, the nurse effect nearly disappeared, being the plant cover beneath and outside nurse plants almost similar. These results suggest that cattle actively grazed on seedlings of both species homogenizing species cover beneath and outside patches.

Our study highlights the role of $\mathrm{C}$. wagneri as a nurse plant in the rare Ecuadorian dry scrub, in terms of its effect on richness and total plant cover at the microsite and the entire community scale. The effect of nurse plants was transferred to the entire community by means of four perennial species strictly associated with patches of $C$. wagneri. This study remarks the importance of evaluating the joint effect of the two co-occurring stressors (climate and grazing) on plant community attributes, because the 
biotic stress created by herbivores greatly altered the magnitude and could even change the sign of species interactions. This study validates the SGH theory for this dry tropical system, since we detected that the importance of the nurse effect increased with abiotic stress. We conclude that the nurse effect is crucial in regulating community properties both at microsite and at the entire community scales.

\section{ACKNOWLEDGEMENTS}

This work has been partially supported by the following projects: A/030244/10 (Agencia Española de Cooperación Internacional para el Desarrollo - AECID), REMEDINAL2 P2009/AMB-1783 (Madrid Autonomus Government), MOUNTAINS CGL2012-38427 (Spanish Ministry of Science and Innovation), PIC 08139 (Ecuador Secretaria Nacional de Educación Superior Ciencia, Tecnología e Innovación - SENESCYT, www.senescyt.gob.ec), SENESCYT scholarship 2008-2. Thanks to MALCA S.A. for the access to the study area.

\section{LITERATURE CITED}

AGUIAR, M. R. \& SALA, O. E. 1999. Patch structure, dynamics and implications for the functioning of arid ecosystems. Trends in Ecology and Evolution 14:273-277.

ARMAS, C., ORDIALES, R. \& PUGNAIRE, F. I. 2004. Measuring plant interactions: a new comparative index. Ecology 85:2682-2686.

ARMAS, C., PUGNAIRE, F. I. \& SALA, O. E. 2008. Patch structure dynamics and mechanisms of cyclical succession in a Patagonian steppe (Argentina). Journal of Arid Environments 72:1552-1561.

BATES, D. M. \& CHAMBERS, J. M. 1992. Nonlinear models. Pp. 421454 in Chambers, J. M. \& Hastie, T. J. (eds.). Statistical models in S. Wadsworth \& Brooks/Cole, Pacific Grove.

BOWERS, J. 2005. Influence of climatic variability on local population dynamics of a Sonoran Desert Platyopuntia. Journal of Arid Environments 61:193-210.

CALLAWAY, R. M. 1997. Positive interactions in plant communities and the individualistic-continuum concept. Oecologia 112:143-149.

CALLAWAY, R. M. 2007. Positive interactions andinterdependence in plant communities. Springer, Dordrecht. 415 pp.

CAVIERES, L. A. \& BADANO, E. I. 2009. Do facilitative interactions increase species richness at the entire community level? Journal of Ecology 97:1181-1191.

CAVIERES, L. A., BADANO, E. I., SIERRA-ALMEIDA, A., GÓMEZGONZÁLEZ, S. \& MOLINA-MONTENEGRO, M. A. 2006. Positive interactions between alpine plant species and the nurse cushion plant Laretia acaulis do not increase with elevation in the Andes of central Chile. New Phytologist 169:59-69.

CHOLER, P., MICHALET, R. \& CALLAWAY, R. M. 2001. Facilitation and competition on gradients in alpine plant communities. Ecology 82:3295-3308.
CRAIN, C. M. \& BERTNESS, M. D. 2006. Ecosystem engineering across environmental gradients: implications for conservation and management. BioScience 56:211-218.

ESCUDERO, A., GIMÉNEZ-BENAVIDES, L., IRIONDO, J. M. \& RUBIO, A. 2004. Patch dynamics and islands of fertility in a high mountain Mediterranean community. Arctic, Antarctic, and Alpine Research 36:518-527.

ESPINOSA, C. I., CABRERA, O., LUZURIAGA, A. L. \& ESCUDERO, A. 2011. What factors affect diversity and species composition of endangered Tumbesian dry forests in southern Ecuador? Biotropica 43:15-22.

ESPINOSA, C. I., LUZURIAGA, A. L., DE LA CRUZ, M., MONTERO, M. \& ESCUDERO, A. 2013. Co-occurring grazing and climate stressors have different effects on the total seed bank when compared to the persistent seed bank. Journal of Vegetation Science. DOI: $10.1111 /$ jvs. 12043.

GRAFF, P., AGUIAR, M. R. \& CHANETON, E. J. 2007. Shifts in positive and negative plant interactions along a grazing intensity gradient. Ecology 88:188-199.

GRIME, J. P. 1973. Competitive exclusion in herbaceous vegetation. Nature 242:344-347.

GUIJARRO, J. 2011. User's guide to climatol. Agency of State Meteorological Office, Balearic Islands. $33 \mathrm{pp}$.

HACKER, S.D. \&GAINES, S.D. 1997. Some implications of direct positive interactions for community species diversity. Ecology 78:19902003.

JOST, L. 2006. Entropy and diversity. Oikos 113:363-375.

KÖRNER, C. \& PAULSEN, J. 2004. A world-wide study of high altitude treeline temperatures. Journal of Biogeography 31:713-732.

LEGENDRE, P. \& LEGENDRE, L. 1998. Numerical ecology. Elsevier, Amsterdam. 853 pp.

MAALOUF, J. P., LE BAGOUSSE-PINGUET, Y., MARCHAND, L., BÂCHELIER, E., TOUZARD, B. \& MICHALET, R. 2012. Integrating climate change into calcareous grassland management. Journal of Applied Ecology 49:795-802.

MAESTRE, F. \& CORTINA, J. 2005. Remnant shrubs in Mediterranean semi-arid steppes: effects of shrub size, abiotic factors and species identity on understorey richness and occurrence. Acta Oecologica 27:161-169.

MAESTRE, F. T. \& ESCUDERO, A. 2009. Is the patch size distribution of vegetation a suitable indicator of desertification processes? Ecology 90:1729-1735.

MAESTRE, F. T., VALLADARES, F. \& REYNOLDS, J. F. 2005. Is the change of plant-plant interactions with abiotic stress predictable? A meta-analysis of field results in arid environments. Journal of Ecology 93:748-757.

MAESTRE, F. T., CALLAWAY, R. M., VALLADARES, F. \& LORTIE, C. J. 2009. Refining the stress-gradient hypothesis for competition and facilitation in plant communities. Journal of Ecology 97:199205.

MICHALET, R., BROOKER, R. W., CAVIERES, L. A., KIKVIDZE, Z., LORTIE, C. J., PUGNAIRE, F. I., VALIENTE-BANUET, A. \& CALLAWAY, R. M. 2006. Do biotic interactions shape both sides of the humped-back model of species richness in plant communities? Ecology Letters 9:767-73. 
MITTELBACH, G. G., STEINER, C. F., SCHEINER, S. M., GROSS, K. L., REYNOLDS, H. L., WAIDE, R. B., DODSON, S. I. \& GOUGH, L. 2001. What is the observed relationship between species richness and productivity? Ecology 82:2381-2396.

OESTERHELD, M. \& OYARZÁBAL, M. 2004. Grass-to-grass protection from grazing in a semi-arid steppe. Facilitation, competition and mass effect. Oikos 107:576-582.

O'HAR A, R. B. \& KOTZE, D. J. 2010. Do not log-transform count data. Methods in Ecology and Evolution 1:118-122.

PINHEIRO, J. C. \& BATES, D. M. 2000. Mixed-Effects Models in S and S-PLUS. Springer, New York. 530 pp.

RUYLE, G. B. \& DWYER, D. D. 1985. Feeding stations of sheep as an indicator of diminished forage supply. Journal of Animal Sciences 61:349-353.

SCHEINER, S. M. \& JONES, S. 2002. Diversity, productivity and scale in Wisconsin vegetation. Evolutionary Ecology Research 4:10971117.

SENFT, R. L., COUGHENOUR, M. B., BAILEY, D. W., RITTENHOUSE, L. R., SALA, O. E. \& SWIFT, D. M. 1987. Large herbivore foraging and ecological hierarchies. BioScience 37:789-799.

SIERRA, R. 1999. Propuesta preliminar de un sistema de clasificación de vegetación para el Ecuador continental. Proyecto INEFAN/GEF-BIRF y EcoCiencia, Quito. 193 pp.

SOLIVERES, S., ELDRIDGE, D. J., MAESTRE, F. T., BOWKER, M. A., TIGHE, M. \& ESCUDERO, A. 2011. Microhabitat amelioration and reduced competition among understorey plants as drivers of facilitation across environmental gradients: towards a unifying framework. Perspectives in Plant Ecology, Evolution and Systematics 13:247-258.

TEWKSBURY, J. J. \& LLOYD, J. D. 2001. Positive interactions under nurse-plants: spatial scale, stress gradients and benefactor size. Oecologia 127:425-434.

TONGWAY, D. J. \& HINDLEY, N. L. 2004. Landscape Function Analysis: procedures for monitoring and assessing Iandscapes. With special reference to minesites and rangelands. CSIRO Sustainable Ecosystems, Canberra. $82 \mathrm{pp}$.

ULLOA, C. \& JØRGENSEN, P. M. 1995. Árboles y arbustos de los Andes deI Ecuador. Department of Systematic Botany. Aarhus University. 264 pp.

WALTER, H. \& LIETH, H. 1960. Klimadiagramm Weltatlas. G. Fischer, Jena. $253 \mathrm{pp}$.

WARREN, R. J. 2010. An experimental test of well-described vegetation patterns across slope aspects using woodland herb transplants and manipulated abiotic drivers. New Phytologist 185:1038-1049.

WHITE, H. 1996. Estimation, inference and specification analysis. Cambridge University Press, Cambridge. 396 pp.

XU, J., MICHALET, R., ZHANG, J. L., WANG, G., CHU, C. J. \& XIAO, S. 2010. Assessing facilitative responses to a nurse shrub at the community level: the example of Potentilla fruticosa in a sub-alpine grassland of northwest China. Plant Biology 12:780-787. 